\title{
Enhancement Photocatalytic Activity of the Heterojunction of Two-Dimensional Hybrid Semiconductors $\mathrm{ZnO} / \mathrm{V}_{2} \mathrm{O}_{5}$
}

\author{
Juan Aliaga ${ }^{1}$ (i) , Nasla Cifuentes ${ }^{1}$, Guillermo González ${ }^{3,4, *}$, Clivia Sotomayor-Torres ${ }^{5,6}$ (1) \\ and Eglantina Benavente $1,2, *$ iD \\ 1 Departamento de Química, Facultad de Ciencias Naturales, Universidad Tecnológica Metropolitana, \\ Matemáticas y Medio Ambiente, P.O. Box 9845, Santiago, Chile; jaliaga@utem.cl (J.A.); \\ nas.cifuentes@gmail.com (N.C.) \\ 2 Programa Institucional de Fomento a la I+D+i, Universidad Tecnológica Metropolitana, \\ Ignacio Valdivieso 2409, P.O. Box 8940577, San Joaquín, Santiago, Chile \\ 3 Departamento de Química, Facultad de Ciencia, Universidad de Chile, P.O. Box 653, Santiago, Chile \\ 4 Center for the Development of Nanoscience and Nanotechnology, CEDENNA, \\ Av. Ecuador 3493, Santiago, Chile \\ 5 Catalan Institute of Nanoscience and Nanotechnology (ICN2), CSIC and BIST, Campus UAB Bellaterra, \\ 08193 Barcelona, Spain; clivia.sotomayor@icn2.cat \\ 6 ICREA, Pg. Lluís Companys 23, 08010 Barcelona, Spain \\ * Correspondence: ggonzale@uchile.cl (G.G.); ebenaven@utem.cl (E.B.); \\ Tel.: +56-22-978-7404 (G.G.); +56-22-787-7109 (E.B.)
}

Received: 30 July 2018; Accepted: 27 August 2018; Published: 4 September 2018

\begin{abstract}
In this work, we report the fabrication of the new heterojunction of two 2D hybrid layered semiconductors - $\mathrm{ZnO}$ (stearic acid) $/ \mathrm{V}_{2} \mathrm{O}_{5}$ (hexadecylamine) - and its behavior in the degradation of aqueous methylene blue under visible light irradiation. The optimal photocatalyst efficiency, reached at a $\mathrm{ZnO}$ (stearic acid) $/ \mathrm{V}_{2} \mathrm{O}_{5}$ (hexadecylamine) ratio of 1:0.25, results in being six times higher than that of pristine zinc oxide. Reusability test shows that after three photocatalysis cycles, no significant changes in either the dye degradation efficiency loss, nor the photocatalyst structure, occur. Visible light photocatalytic performance observed indicates there is synergetic effect between both 2D nanocomposites used in the heterojunction. The visible light absorption enhancement promoted by the narrower bandgap $\mathrm{V}_{2} \mathrm{O}_{5}$ based components; an increased photo generated charge separation favored by extensive interface area; and abundance of hydrophobic sites for dye adsorption appear as probable causes of the improved photocatalytic efficiency in this hybrid semiconductors heterojunction. Estimated band-edge positions for both conduction and valence band of semiconductors, together with experiments using specific radical scavengers, allow a plausible photodegradation mechanism.
\end{abstract}

Keywords: photocatalysis; heterojunction; two-dimensional semiconductor; $\mathrm{ZnO} ; \mathrm{V}_{2} \mathrm{O}_{5}$; Methylene blue degradation

\section{Introduction}

The use of solar energy is increasingly needed to address many of the growing energy and environmental problems facing humanity. Processes like the production of clean fuels from abundant natural resources or the degradation of pollutants based on sunlight-driven reactions, catalyzed by nanostructured semiconducting metal oxides, have received much attention during the last decades [1,2]. These are heterogeneous processes where the role of the photocatalyst is like that of the 
electrodes in electrolysis in the sense of promoting, separately but simultaneously, a redox reactions pair with given substrates adsorbed on its surface. The conversion of radiation energy into chemical energy mainly depends on both, the ability of the semiconductor for creating effective redox centers on its surface and the tendency of the substrate to be adsorbed nears these sites. The photoinduced creation of active redox sites starts with the excitation of electrons from the valence band of the semiconductor to the conduction one, by the absorption of light with energy equal to or greater than its band-gap generating electron-hole pairs $\left(\mathrm{e}^{-} / \mathrm{h}^{+}\right)$. After the separation of these charge pairs, mediated by internal or external electric fields, electrons and holes migrate to spatially separated places at the interface between the particle with its environment, where they can respectively reduce or oxidize suitable substrates [3,4].

The use of wide band, high valence metal oxides, such as $\mathrm{TiO}_{2}$ and more recently $\mathrm{ZnO}$, as photocatalysts have been extensively studied. The electronic structure of these semiconductors, particularly the position of their valence band edge (about $3.0 \mathrm{eV}$ vs. NHE), provides interesting photochemical activity and high resistance to photocorrosion in water solutions; this, together with their generally non-toxicity and low cost, make them promissory for large-scale environmental remediation applications $[5,6]$. However, their photocatalytic efficiency and thus their large-scale applications, is affected by some of their intrinsic properties. Among them, a narrow absorption window that excludes much of the solar spectrum; high recombination rates of light-induced charges leading to poor quantum yields; and relatively high hydrophilic surfaces unfavorable for the adsorption of non-polar substrates [7]. Many efforts have been invested in solving these hindrances. Although most reports on this subject concern $\mathrm{TiO}_{2}$, during the last years $\mathrm{ZnO}$ a n-type semiconductor with direct band gap $(3.37 \mathrm{eV})$ and high exciton binding energy $(60 \mathrm{meV})$, has received increasing attention $[8,9]$. The role of the morphology of $\mathrm{ZnO}$ nanostructures on its photocatalytic performance in the decomposition of organic molecules is being intensively studied [10,11]. In general, anisotropic micro/nanostructures are more efficient because, together with promoting charge carrier generation rate (nanoscale), they allow a higher mean-path-length for the photoinduced charges. This, among others, reduces charge-carriers' recombination, promotes effective charge separation and makes more facile the migration of charge carriers to their reaction sites. Similar effects have been attained by loading noble metals such as $\mathrm{Au}, \mathrm{Ag}, \mathrm{Pd}$ and $\mathrm{Pt}$ as co-catalysts [12-14] and by the formation of $\mathrm{ZnO}$ heterojunctions with other semiconductors like $\mathrm{TiO}_{2}, \mathrm{BiVO}_{4}, \mathrm{Ag}_{2} \mathrm{O}$ or $\mathrm{Cu}_{2} \mathrm{O}$ [14-18]. Numerous attempts to extend the light absorption window of $\mathrm{ZnO}$-naturally centered in the ultraviolettowards lower energies have been also reported [19]. $\mathrm{ZnO}$ sensitization by heterojunction with a relatively minor amount of a second lower band gap semiconductor like $\mathrm{CdS}$ or $\mathrm{WO}_{3}[20,21]$ has been demonstrated to effectively improve its photocatalytic activity under visible light. In these systems, the main absorber is the secondary semiconductor while the role of $\mathrm{ZnO}$ is principally limited to the charge curriers transport. That notwithstanding, some interesting approaches to directly improve $\mathrm{ZnO}$ visible-light absorption have been also attempted; namely by creating electronic levels within the $\mathrm{ZnO}$ band gap, by metal or non-metal doping, or surface modification via organic materials grafting [22-25]. Most attempts to improve the photocatalysis of organic contaminants by optimizing the adsorption of the substrates upon the photocatalyst mainly concern the increment of its specific surface area, so the utilization of 2D layered materials that have larger specific surface areas-a great number of active sites on the surface and superior electron mobility that facilitates the transfer and separation of photogenerated electrons and holes-is a good strategy for constructing effective photocatalyst [26,27]. Approach considering additives to increase the hydrophobicity of the semiconductor surface, like the use of surfactants reported for $\mathrm{TiO}_{2}$ are in general scarce for $\mathrm{ZnO}$ [25,28-32]. In this direction, we recently developed laminar hybrid 2D ZnO-organic nanocomposites in which the surfactant, grafted to the inorganic matrix, significantly improves the photocatalytic process [33]. The sensitization of $\mathrm{ZnO}$ with $\mathrm{V}_{2} \mathrm{O}_{5}$ species has been previously informed; for example, Yin et al. reported enhanced photocatalytic degradation of methylene blue (MB) in $\mathrm{V}_{2} \mathrm{O}_{5} / \mathrm{ZnO}$ heteronanorods [34], Zou et al. reported the decomposition of chlorophenol asisted by $\mathrm{ZnO} / \mathrm{V}_{2} \mathrm{O}_{5}$ core-shell nanostructures [35], 
and Aslam et al. reported the decomposition of nitrophenol with bare $\mathrm{ZnO} / \mathrm{V}_{2} \mathrm{O}_{5}$ mixtures [36]. The capability of $\mathrm{V}_{2} \mathrm{O}_{5}$ to sensitize the $\mathrm{ZnO}$ nanocomposite makes the system a very attractive and new material for studied of heterogeneous photocatalysis.

In this work, we evaluated the photocatalytic activity of the organic-inorganic laminar $\mathrm{ZnO}$ (stearic acid) with a band gap (Eg) of $3.28 \mathrm{eV}$, combined with organic-inorganic hybrid $\mathrm{V}_{2} \mathrm{O}_{5}$ (hexadecylamine), $(\mathrm{Eg}=3.28)$ in the degradation of aqueous methylene blue solution in visible light. In addition, we have realized various combinations with $\mathrm{V}_{2} \mathrm{O}_{5}$ and $\mathrm{V}_{2} \mathrm{O}_{5}$-xerogel to investigate the photocatalytic activity. The blend of both organic-inorganic hybrid semiconductors 2D/2D produces the expected synergy improving the degradation of the dye selected as organic contaminant model. Furthermore, tentative mechanism was also discussed based on the active species trapping experiments and estimated band edge positions.

\section{Results and Discussion}

The XRD pattern of synthesized nanocomposites are shown in Figure 1. The lamellar nature of $\mathrm{ZnO}$ (stearic acid) $(\mathrm{ZnO}(\mathrm{SA}))$, shown in Figure $1 \mathrm{a}$, and $\mathrm{V}_{2} \mathrm{O}_{5}$ (hexadecylamine) $\left(\mathrm{V}_{2} \mathrm{O}_{5}(\mathrm{HDA})\right)$, shown in Figure $1 \mathrm{~b}$, which were constituted of single nanosheets of semiconductor sandwiched between self-assembled surfactants, is confirmed by the X-ray diffraction patterns. These display low angle reflections, characteristic of well-ordered laminar arrangements $2 \mathrm{D}$, according to the positions of the 001 reflections in the diffraction pattern. The interlayer distances along the c-axis correspond to the first peak in the low angle XRD pattern, which correlate well with the molecular lengths of corresponding carboxylic acid and alkylamine, previously reported [37,38]. In Figure 1a also shows the reflections that indicate the inorganic moiety corresponding to $\mathrm{ZnO}$ single phase with the wurtzite structure (JCPDS 36-1451). Figure $1 \mathrm{c}$ shows the $\mathrm{XRD}$ patterns of heterojunction $\mathrm{ZnO}(\mathrm{SA}) / \mathrm{V}_{2} \mathrm{O}_{5}(\mathrm{HDA})$; two types of phases were detected, a phase well defined of $\mathrm{ZnO}(\mathrm{SA})$ and a 001 plane to $\mathrm{V}_{2} \mathrm{O}_{5}(\mathrm{HDA})$, reveal the formation of layered structure with both composites. In this XRD pattern, no other possible impurities were detected which do suggest that nanocomposites $\mathrm{ZnO}(\mathrm{SA})$ and $\mathrm{V}_{2} \mathrm{O}_{5}(\mathrm{HDA})$ remains unaltered.

The chemical states of the $\mathrm{ZnO}(\mathrm{SA}) / \mathrm{V}_{2} \mathrm{O}_{5}(\mathrm{HDA})$ composite were investigated by $\mathrm{X}$-ray photoelectron spectra (XPS) as shown in Figure 2. The XPS survey spectra (Figure S1) indicate the presence of $\mathrm{Zn}, \mathrm{V}, \mathrm{O}$ and $\mathrm{C}$ in the surface of the composite. The deconvolution of the high-resolution spectra for $Z n 2 p, V 2 p$ and $O$ 1s is shown in the Figure $2 a-c$. The binding energies for the $Z n 2 p_{3 / 2}$ and $2 \mathrm{p}_{1 / 2}$ core levels at $1021.6 \mathrm{eV}$ and $1044.6 \mathrm{eV}$ respectively in Figure $2 \mathrm{a}$, indicates the presence of $\mathrm{ZnO}$ in the composite. The Figure $2 b$, show the $\mathrm{V} 2 \mathrm{p}_{3 / 2}$ spectrum of the composite, with two components centered at $516.8 \mathrm{eV}$ and $515.5 \mathrm{eV}$, corresponding to the binding energies for the $\mathrm{V}^{5+}$ and $\mathrm{V}^{4+}$ species, in agreement with the presence of $\mathrm{V}_{2} \mathrm{O}_{5}$ and $\mathrm{VO}_{2}$ [39]. The $\mathrm{O} 1 \mathrm{~s}$ spectrum (Figure 2c) contains two peaks, at $530 \mathrm{eV}$ and $531 \mathrm{eV}$ with characteristic binding energies for O-oxidation state and the peak at $531-532 \mathrm{eV}$ has been assigned to the oxygen of surfactants of the composite [40].

Scanning electron microscopy (SEM) were performed to investigate the morphology and microstructures of nanocomposite samples. The morphology of nanocomposites is illustrated in the micrographics in Figure 3. The SEM image shows in Figure $3 a, b$ the layered nature of $\mathrm{ZnO}(\mathrm{SA})$ and $\mathrm{V}_{2} \mathrm{O}_{5}(\mathrm{HDA})$ while its microstructured surface, with multi-layer laminas. Figure $3 \mathrm{c}$ presents the SEM images of the representative $\mathrm{ZnO}(\mathrm{SA}) / \mathrm{V}_{2} \mathrm{O}_{5}(\mathrm{HDA})$ heterojunction and EDX patterns of confirm the presence of all constituent elements of the heterojunction. No other remarkable impurities were observed. In Figure S2 SEM images of $\mathrm{ZnO}(\mathrm{SA}) / \mathrm{V}_{2} \mathrm{O}_{5}(\mathrm{HDA})$ and element mappings were further performed, and it can be seen clearly that $\mathrm{Zn}$ and $\mathrm{V}$ are evenly distributed, indicating the formation of hybrid nanostructure. 


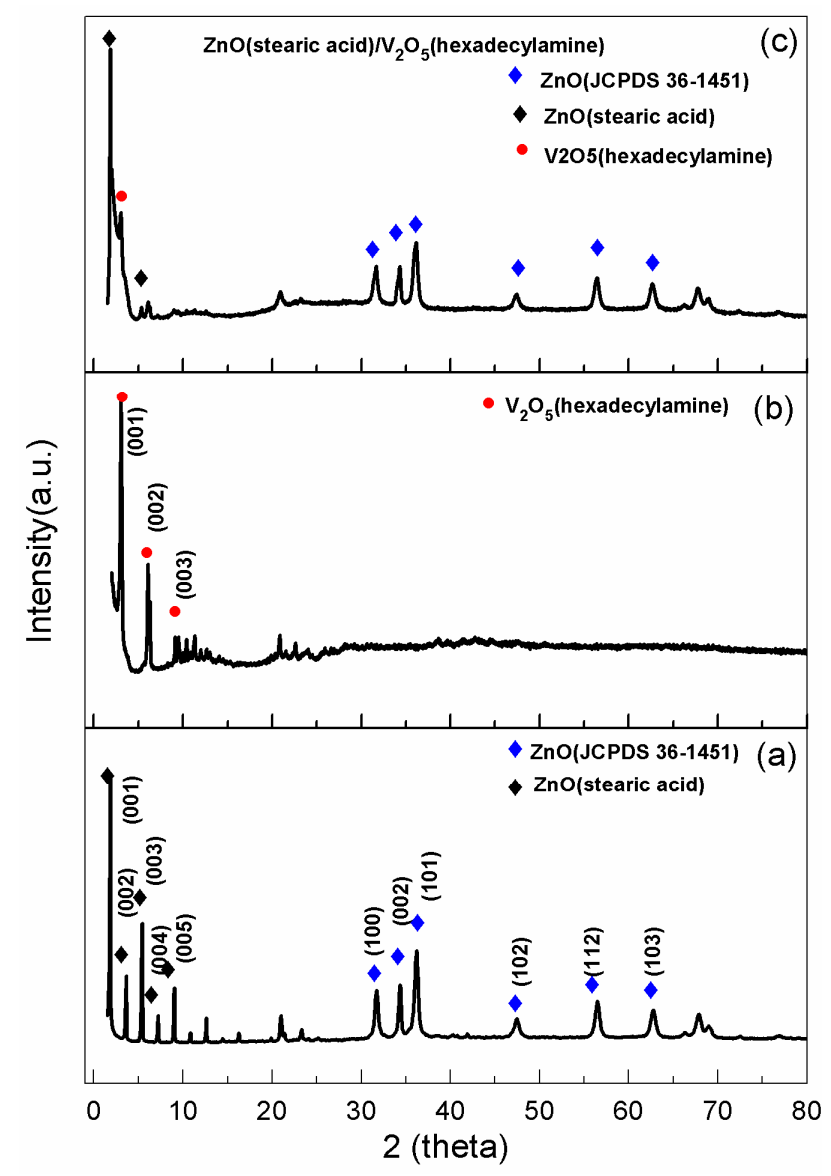

Figure 1. (a) XRD pattern of $\mathrm{ZnO}(\mathrm{SA})$; (b) XRD pattern of $\mathrm{V}_{2} \mathrm{O}_{5}(\mathrm{HDA}$ ); and (c) XRD pattern of nanocomposite heterojunction $\mathrm{ZnO}(\mathrm{SA}) / \mathrm{V}_{2} \mathrm{O}_{5}(\mathrm{HDA})$.
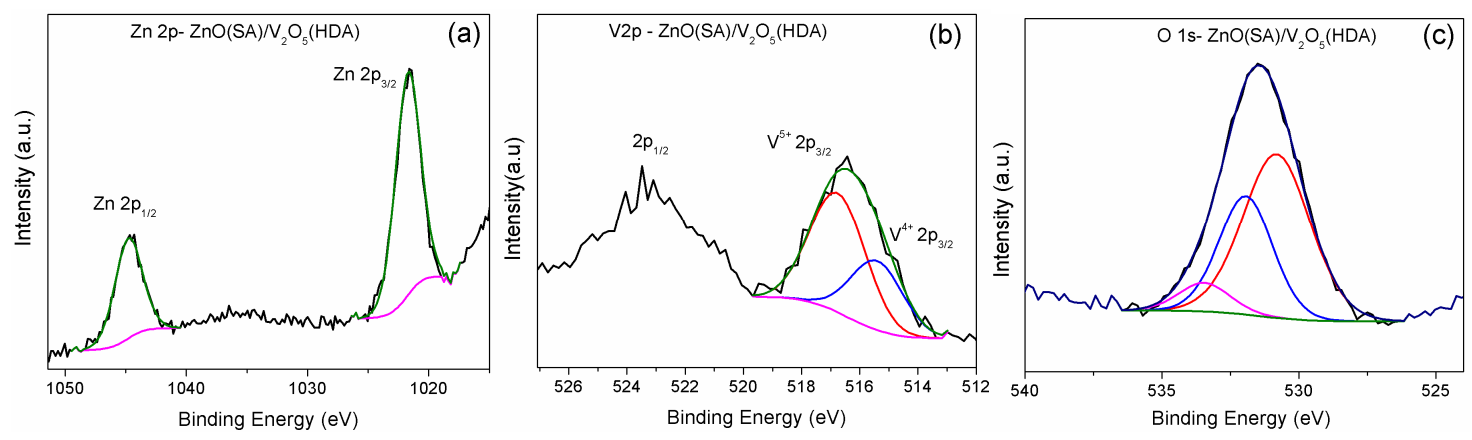

Figure 2. XPS spectra of core level (a) Zn2p, (b) V2p and (c) O1s. 

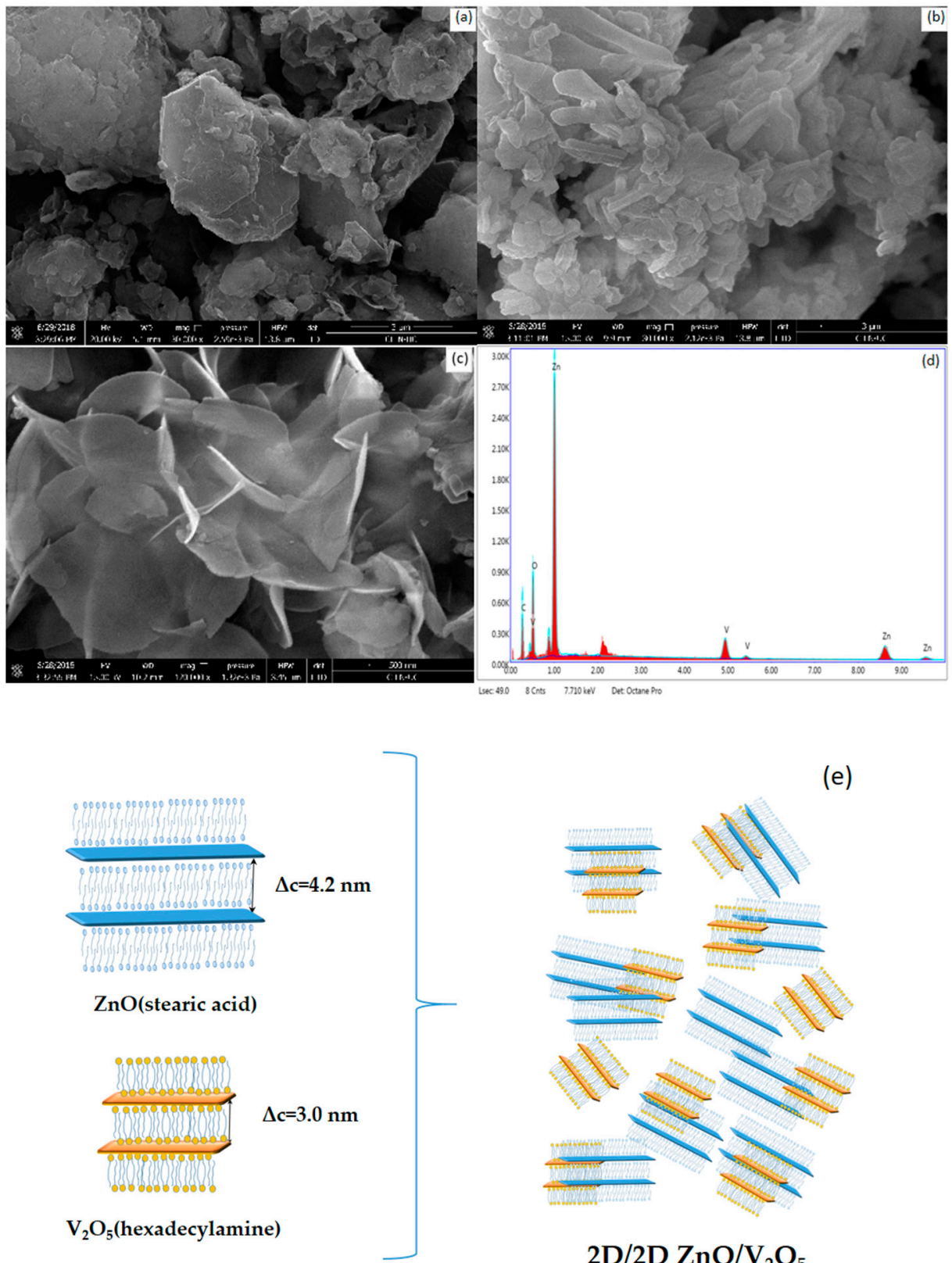

(e)

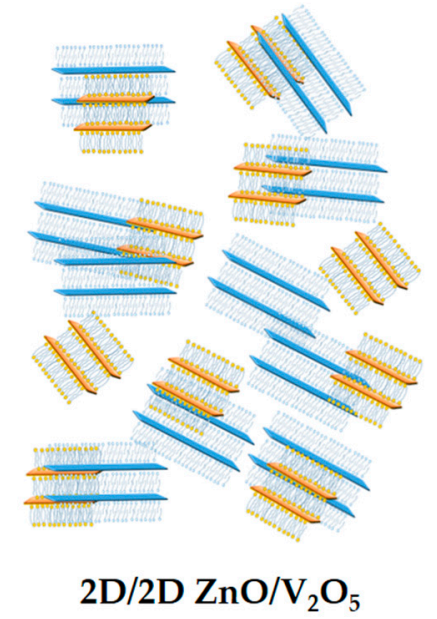

Figure 3. (a) SEM micrographs $\mathrm{ZnO}(\mathrm{SA})$; (b) SEM micrographs $\mathrm{V}_{2} \mathrm{O}_{5}(\mathrm{HDA}$ ); (c) SEM micrographs $\mathrm{ZnO}(\mathrm{SA}) / \mathrm{V}_{2} \mathrm{O}_{5}(\mathrm{HDA})$; (d) EDX pattern and (e) Schematic representation 2D/2D heterojunction.

The UV-visible diffuse reflectance was measured for $\mathrm{ZnO}(\mathrm{SA}), \mathrm{V}_{2} \mathrm{O}_{5}(\mathrm{HDA})$ and $\mathrm{ZnO}(\mathrm{SA}) / \mathrm{V}_{2} \mathrm{O}_{5}(\mathrm{HDA})$ to determine their light absorption characteristics (Figure S3). The wavelength distribution of the absorbed light is an important property of photocatalysts, irrespective of the quantum yield. Therefore, the high photoactivity was attributed to higher visible light absorbance, as indicated by the UV-visible diffuse reflectance spectroscopy. The absorption bands in the range of $200-400 \mathrm{~nm}$, observed in all spectra, suggest strong free exciton absorption at room temperature. The band gap of samples can be estimated from a plot of $(\alpha \mathrm{hv})^{2}$ versus the photon energy and the intercept of a tangent to the $\mathrm{x}$-axis was recorded as shown in Figure $\mathrm{S} 4$ where energies, Eg, determined from the spectra are 3.28 and $2.28 \mathrm{eV}$ for $\mathrm{ZnO}(\mathrm{SA})$ and $\mathrm{V}_{2} \mathrm{O}_{5}(\mathrm{HDA})$ respectively [41]. The variation of the band gap with respect to that of $\mathrm{ZnO}(\mathrm{SA})$ is clearly seen, the absorption edge has a clear shift toward longer wavelengths. 
In Figure $4 \mathrm{a}$ the infrared analysis of $\mathrm{ZnO}(\mathrm{SA})$ shows the peaks in the region $3000-2800 \mathrm{~cm}^{-1}$ assigned to stretching modes of the $\mathrm{C}-\mathrm{H}$ bond of the methylene group, the band at $1705 \mathrm{~cm}^{-1}$ corroborates the presence of $v(\mathrm{C}-\mathrm{O})$ band of the carboxylic acid in the sample and the bands at 1560 and $1315 \mathrm{~cm}^{-1}$ corresponding to the asymmetric and symmetric $v(\mathrm{C}-\mathrm{O})$ modes, respectively, demonstrate that the organic moiety is found as a carboxylate mono-coordinated to the inorganic sheets [42]. In Figure $4 b$, the infrared analysis of $\mathrm{V}_{2} \mathrm{O}_{5}(\mathrm{HDA})$ shows that the peaks in the region $1000 \mathrm{~cm}^{-1}$ are assigned to the stretching vibration of $\mathrm{V}=\mathrm{O}$, the frequencies correspond to $\mathrm{V}=\mathrm{O}$ group of the vanadyl oxygen in 1011, $997 \mathrm{~cm}^{-1}$ and $\mathrm{V}-\mathrm{O}-\mathrm{V}$ asymmetric stretching in $737 \mathrm{~cm}^{-1}$ of $\mathrm{V}_{2} \mathrm{O}_{5}$. The stretching modes of the $\mathrm{C}-\mathrm{H}$ bond of the methylene group at $3000-2800 \mathrm{~cm}^{-1}$. The spectrum shows a shoulder at $3136 \mathrm{~cm}^{-1}$ attributed to the $\mathrm{N}-\mathrm{H}$ vibrational stretching mode of the hexadecylamine surfactant of the nanocomposite [43]. The spectrum infrared the $\mathrm{ZnO}(\mathrm{SA}) / \mathrm{V}_{2} \mathrm{O}_{5}(\mathrm{HDA})$ composite in Figure $4 \mathrm{c}$ shows characteristics bands of both components. The observation in all IR spectra of $\mathrm{H}-\mathrm{O}-\mathrm{H}$ vibrational modes in the region $3500 \mathrm{~cm}^{-1}$ indicates a detectable presence of remnant water molecules.

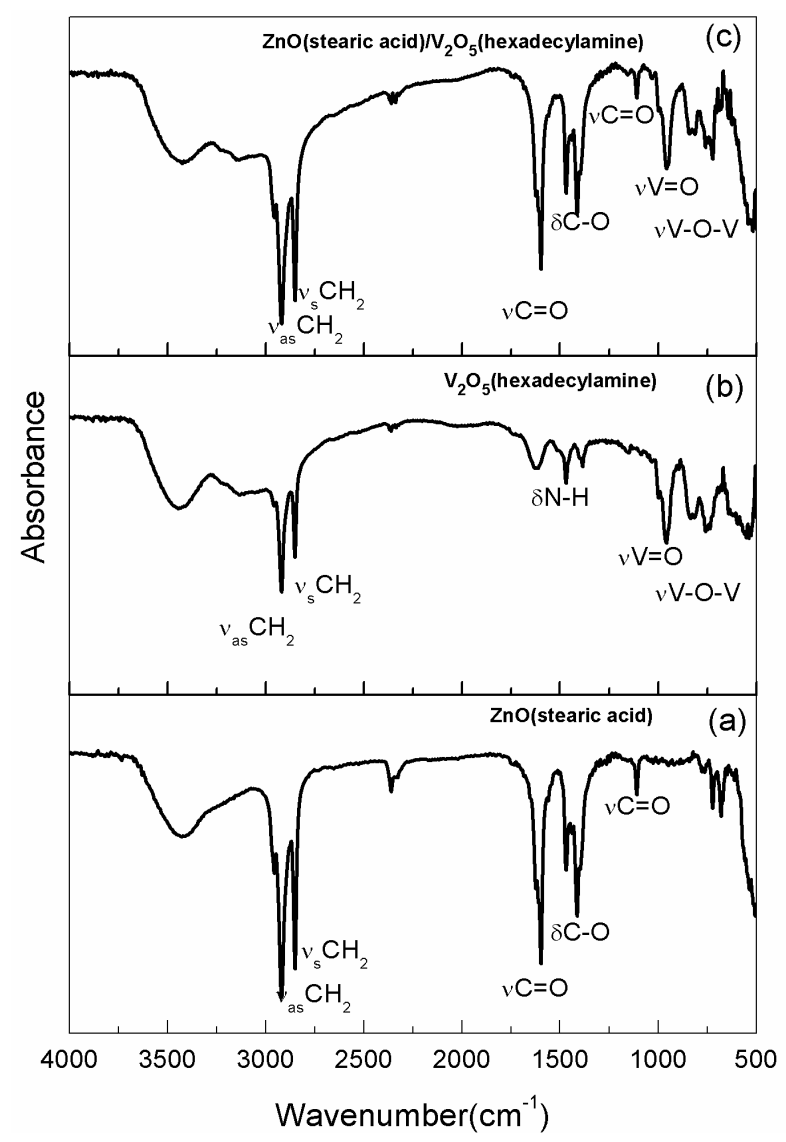

Figure 4. (a) FTIR absorbance spectra of $\mathrm{ZnO}(\mathrm{SA})$ (b) FTIR absorbance spectra of $\mathrm{V}_{2} \mathrm{O}_{5}(\mathrm{HDA})$ and (c) FTIR spectra of $\mathrm{ZnO}(\mathrm{SA}) / \mathrm{V}_{2} \mathrm{O}_{5}$ (HDA).

\section{Photocatalytic Activity}

The photocatalytic activity of nanocomposites and their heterojunctures was studied by visible light degradation of methylene blue as a pollutant model. We investigated the photocatalytic behavior a series of samples with different $\mathrm{ZnO} / \mathrm{V}_{2} \mathrm{O}_{5}$ molar ratios prepared by mixing $\mathrm{ZnO}(\mathrm{SA})$ and $\mathrm{V}_{2} \mathrm{O}_{5}$ orthorhombic, $\mathrm{V}_{2} \mathrm{O}_{5}$-xerogel or $\mathrm{V}_{2} \mathrm{O}_{5}(\mathrm{HDA})$ as described in Table S1. The photocatalytic properties of the as-prepared samples were evaluated under similar conditions and all curves were normalized after reaching the adsorption/desorption equilibrium (Figure S5). The results in Figure 5a shows that the sample of the heterojunction $\mathrm{ZnO}(\mathrm{SA}) / \mathrm{V}_{2} \mathrm{O}_{5}(\mathrm{HDA})$ 1:0.25 exhibits the highest photocatalytic 
efficiency in visible light irradiation. The comparison of catalytic activity of these samples indicated that $90 \%$ of the MB dye was degraded after $400 \mathrm{~min}$ of irradiation, the luminance of the light source was 0.5 Sun. Meanwhile, the hybrid heterostructure $\mathrm{ZnO}(\mathrm{SA}) / \mathrm{V}_{2} \mathrm{O}_{5}(\mathrm{HDA})$ 1:0.5 shows lower photocatalytic ability than the other samples, which could be attributed to the higher concentration of $\mathrm{V}_{2} \mathrm{O}_{5}$ acting as a recombination center for photogenerated charge carriers and increasing the sample opacity, obstructing the light absorption and decreasing the photocatalytic activity [17]. Photocatalytic processes are very complex, and some aspects of the reaction kinetics are being studied. In this work, the photocatalytic degradation of methylene blue could be described by pseudo-first-order kinetics, $\ln \left(C_{0} / C\right)=k t$, where $\mathrm{k}$ is the corresponding kinetic constant and $\mathrm{t}$ the irradiation time Figure $5 \mathrm{~b}$. The apparent rate constants $\left(\mathrm{k}_{\mathrm{app}}, \mathrm{min}^{-1}\right)$ hybrid $\mathrm{ZnO}(\mathrm{SA}) / \mathrm{V}_{2} \mathrm{O}_{5}(\mathrm{HDA})$ was about 6 time faster than for $\mathrm{ZnO}$. The rate constants were calculated and the linear regression coefficients $\left(\mathrm{R}^{2}\right)$ for all samples under visible light.
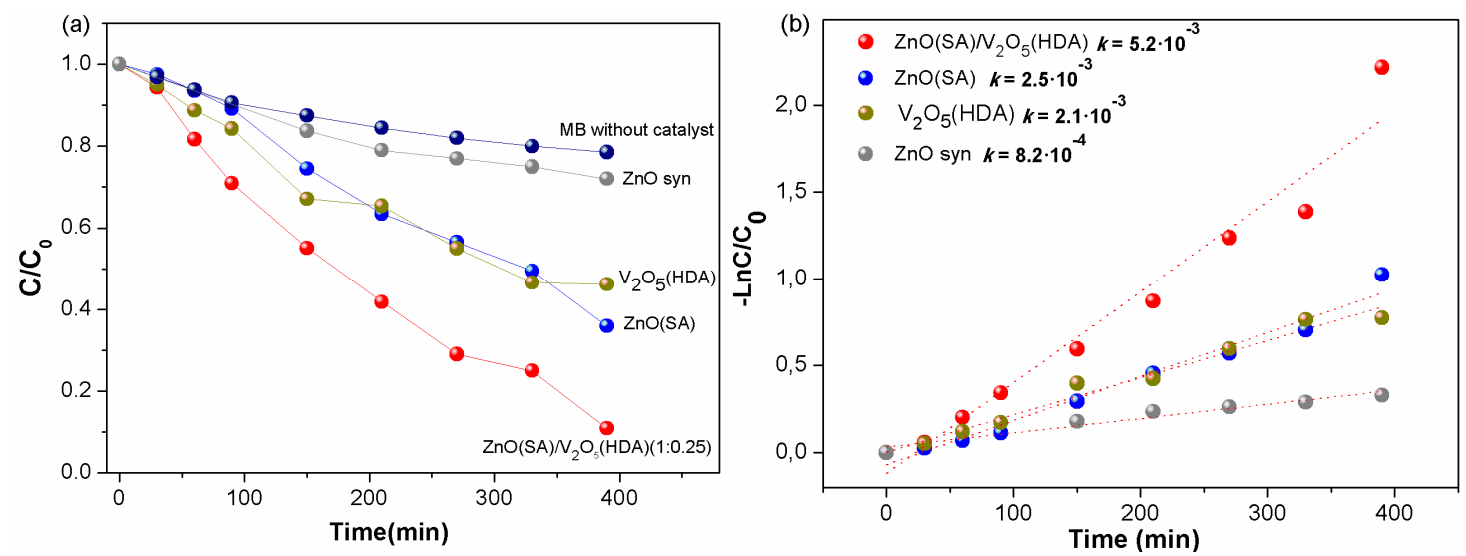

Figure 5. (a) Photocatalytic performance of the samples $\mathrm{ZnO}(\mathrm{SA}) / \mathrm{V}_{2} \mathrm{O}_{5}(\mathrm{HDA})$ for the degradation of MB solution and the degradation of MB without photocatalyst. (b) Photodegradation kinetics of the selected samples for the degradation of MB solution.

These results agree qualitatively with reports on the improvement of the photocatalytic efficiency of stratified hybrid $\mathrm{ZnO}[33,37]$. The shape of the $\mathrm{MB}$ spectrum remains unchanged throughout the process and no organic by products were detected, indicating the degradation of the dye (Figure S6). The photocatalytic performance of visible light observed indicates that there is a synergistic effect between both 2D nanocomposites used. In these heterojunctions the large face-to-face contact between the sheets, which provide more reaction sites for the adsorption of contaminants exhibiting greater stability, should lead to the interfacial charge transfer efficiency $[26,27]$. the presence of the organic surfactant in the interlaminar spaces of $\mathrm{ZnO}$ and $\mathrm{V}_{2} \mathrm{O}_{5}$ favors the adsorption of dye on the surface of semiconductors thus the abundance of hydrophobic sites for the adsorption of dye appears as a probable cause of improved photocatalytic efficiency in this hybrid semiconductors heterojunction.

To further investigate the role of active species such as $\mathrm{h}^{+}, \bullet^{\bullet} \mathrm{OH}$ and $\mathrm{O}_{2}{ }^{-\bullet}$ in the photocatalytic degradation of dye, active species trapping experiments were performed using the sample $\mathrm{ZnO}(\mathrm{SA})$, $\mathrm{V}_{2} \mathrm{O}_{5}(\mathrm{HDA})$ and $\mathrm{ZnO}(\mathrm{SA}) / \mathrm{V}_{2} \mathrm{O}_{5}(\mathrm{HDA})$ 1:0.25. For these experiments, oxalate of ammonium (OA) was used as hole $\left(\mathrm{h}^{+}\right)$scavenger $(2 \mathrm{mM})$, isopropanol (IPA) as a ${ }^{\bullet} \mathrm{OH}$ scavenger $(2 \mathrm{mM})$ and chloroform $\left(\mathrm{CHCl}_{3}\right)$ as an $\mathrm{O}_{2}{ }^{-\bullet}$ scavenger $(2 \mathrm{mM})$ [44-46]. The impact of different scavengers is shown in Figure 6a, for $\mathrm{ZnO}(\mathrm{SA})(64 \%)$, when the $\mathrm{CHCl}_{3}$ was added into reaction solution, the photocatalytic degradation is almost invariable $(60 \%)$. However, when the IPA and OA were added into solution, the degradation rate of $\mathrm{MB}$ was inhibited ( $44 \%$ and $47 \%$, respectively). Thus, the ${ }^{\bullet} \mathrm{OH}$ and $\mathrm{h}^{+}$radicals are the major reactive species in the $\mathrm{ZnO}(\mathrm{SA})$ reaction. For $\mathrm{V}_{2} \mathrm{O}_{5}(\mathrm{HDA})(48 \%)$, when the IPA was added to the reaction solution photocatalytic degradation drops to $5 \%$ indicating that ${ }^{\bullet} \mathrm{OH}$ is the major reactive species in the reaction. On the other hand, for the $\mathrm{ZnO}(\mathrm{SA}) / \mathrm{V}_{2} \mathrm{O}_{5}(\mathrm{HDA})$ sample (90\%), when the OA 
and IPA were added, the photocatalytic degradation rate was decreased (53\% and 54\%, respectively) indicating the $\mathrm{h}^{+}$and ${ }^{\bullet} \mathrm{OH}$ are the predominant active species. When the $\mathrm{CHCl}_{3}$ was added to the reaction solution, the degradation rate of the inhibited slightly $(68 \%)$, suggesting the $\mathrm{O}_{2}{ }^{-\bullet}$ affects less in the photocatalysis process. Thus, from these experiments, we conclude ${ }^{\bullet} \mathrm{OH}$ and $\mathrm{h}^{+}$as major active species in photocatalytic degradation of MB under visible light irradiation.
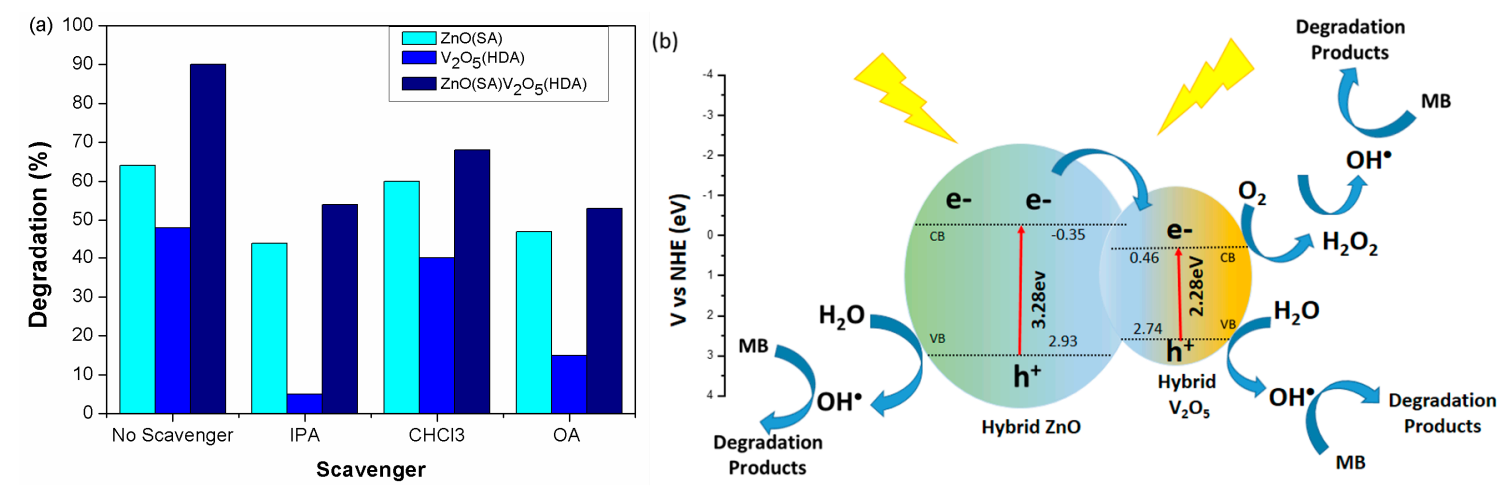

Figure 6. (a) Photocatalytic degradation of $\mathrm{MB}$ under visible light after addition of several trapping reagents (b) Possible mechanism of the photocatalytic activity of $\mathrm{ZnO}(\mathrm{SA}) / \mathrm{V}_{2} \mathrm{O}_{5}(\mathrm{HDA})$ for degradation under visible light irradiation.

The activity of photocatalyst depends of the effective separation of electron-hole pairs and the migration of the photogenerated charge is related to the band edge position in conduction band (CB) and valence band $(\mathrm{VB})$ of semiconductors. The band positions $\left(\mathrm{E}_{\mathrm{CB}}\right.$ and $\left.\mathrm{E}_{\mathrm{VB}}\right)$ for the hybrids $\mathrm{ZnO}$ and $\mathrm{V}_{2} \mathrm{O}_{5}$ were calculated applying the equations reported in the literature [46]:

$$
\begin{gathered}
E_{C B}=x-E^{e}-\frac{1}{2} E_{g} \\
E_{C B}=E_{V B}-E_{g}
\end{gathered}
$$

where $\chi$ is the electronegativity of semiconductors $\mathrm{ZnO}$ and $\mathrm{V}_{2} \mathrm{O}_{5}$ (5.79 and $6.10 \mathrm{eV}$, respectively); $\mathrm{E}^{\mathrm{e}}$ is the energy of free electrons on the hydrogen scale $(4.5 \mathrm{eV})$; and the band gap energy $\left(\mathrm{E}_{\mathrm{g}}\right)$ of the semiconductor calculated from DRS data [40]. The calculated CB and VB edge positions of hybrid $\mathrm{ZnO}$ are $-0.35 \mathrm{eV}$ and $2.93 \mathrm{eV}$. As for hybrid $\mathrm{V}_{2} \mathrm{O}_{5}$, the $\mathrm{CB}$ and $\mathrm{VB}$ edge positions are $0.46 \mathrm{eV}$ and $2.74 \mathrm{eV}$, respectively.

Therefore, when the photon energy higher or equal to band gap energy of $\mathrm{ZnO}$ and $\mathrm{V}_{2} \mathrm{O}_{5}$, electrons can be excited from the VB to the $\mathrm{CB}$ with simultaneous generation of holes in the VB. Due to the $\mathrm{CB}$ of $\mathrm{ZnO}(\mathrm{SA})$ is more negative than that of the $\mathrm{V}_{2} \mathrm{O}_{5}(\mathrm{HDA})$, electrons on the $\mathrm{CB}$ of $\mathrm{ZnO}(\mathrm{SA})$ can be easily injected into the $\mathrm{CB}$ of $\mathrm{V}_{2} \mathrm{O}_{5}(\mathrm{HDA})$ by the interface. The photogenerated electrons on the $\mathrm{CB}$ of $\mathrm{V}_{2} \mathrm{O}_{5}$ (HDA) could not produce $\mathrm{O}_{2}{ }^{-\bullet}$ from dissolved $\mathrm{O}_{2}$, due to the position of $\mathrm{CB}$ is more positive than the potential of $\mathrm{O}_{2} / \mathrm{O}_{2}{ }^{-\bullet}\left(-0.33 \mathrm{~V}\right.$ vs. NHE). However, the reduction potential of $\mathrm{O}_{2} / \mathrm{H}_{2} \mathrm{O}_{2}$ is $0.695 \mathrm{eV}$ vs. NHE, means electrons can react with $\mathrm{O}_{2}$ and $\mathrm{H}^{+}$to produce $\mathrm{H}_{2} \mathrm{O}_{2}$ which indirectly produce - $\mathrm{OH}$ [46]. This is also observed in heterojunctions with other semiconductors like $\mathrm{Ag}_{3} \mathrm{VO}_{4} / \mathrm{WO}_{3}$ [47], $\mathrm{ZnO} / \mathrm{MoS}_{2}$ [45] and $\mathrm{Ag}_{3} \mathrm{PO}_{4} / \mathrm{TiO}_{2}$ [48]. Meanwhile the photoinduced holes in $\mathrm{VB}$ of both $\mathrm{V}_{2} \mathrm{O}_{5}$ and $\mathrm{ZnO}$ can oxidize adsorbed $\mathrm{H}_{2} \mathrm{O}$ molecules to produce ${ }^{\bullet} \mathrm{OH}\left({ }^{\bullet} \mathrm{OH} / \mathrm{H}_{2} \mathrm{O}\right.$ is $2.72 \mathrm{eV}$ vs. NHE).

The mechanism can be described as:

$$
\begin{aligned}
\mathrm{ZnO}(\mathrm{SA}) / \mathrm{V}_{2} \mathrm{O}_{5}(\mathrm{HDA})+\mathrm{h} v(\text { visible }) \rightarrow \mathrm{ZnO}(\mathrm{SA}) / \mathrm{V}_{2} \mathrm{O}_{5}(\mathrm{HDA})\left(\mathrm{h}^{+} \mathrm{VB}+\mathrm{e}^{-} \mathrm{CB}\right) \\
\mathrm{ZnO}(\mathrm{SA})\left(\mathrm{e}^{-} \mathrm{CB}\right) \rightarrow \mathrm{V}_{2} \mathrm{O}_{5}(\mathrm{HDA})\left(\mathrm{e}^{-} \mathrm{CB}\right) \\
\mathrm{ZnO}(\mathrm{SA})\left(\mathrm{h}^{+} \mathrm{VB}\right) \rightarrow \mathrm{V}_{2} \mathrm{O}_{5}(\mathrm{HDA})\left(\mathrm{h}^{+} \mathrm{VB}\right)
\end{aligned}
$$




$$
\begin{gathered}
\mathrm{V}_{2} \mathrm{O}_{5}(\mathrm{HDA})\left(\mathrm{e}^{-} \mathrm{CB}\right)+\mathrm{H}^{+}+\mathrm{O}_{2} \rightarrow \mathrm{H}_{2} \mathrm{O}_{2} \\
\mathrm{H}_{2} \mathrm{O}_{2}+\mathrm{e}^{-}+\mathrm{h} v(\text { visible }) \rightarrow \bullet \mathrm{OH}+\mathrm{OH}^{-} \\
\bullet \mathrm{OH}+\mathrm{h}^{+}+\mathrm{MB} \rightarrow \text { Degradation products }
\end{gathered}
$$

- $\mathrm{OH}$ radicals are very reactive oxidative species to degrade of dye. As illustrated in Figure $6 \mathrm{~b}$, the prepared heterojunctions $\mathrm{ZnO} / \mathrm{V}_{2} \mathrm{O}_{5}$ improve the photogenerated electron-hole pair's separation and transfer, favored by extensive interface area, as well as show an oxidation and reduction ability for efficient degradation of organic pollutants.

Concerning the stability of the photocatalyst, we have also investigated the stability and reusability of the $\mathrm{ZnO}(\mathrm{SA}) / \mathrm{V}_{2} \mathrm{O}_{5}$ (HDA) photocatalyst over three cycles for a period of $400 \mathrm{~min}$ irradiation [46,49]. Figure S7 shows a loss photocatalytic activity of approx. 10\% in which might be due to the loss of the photocatalyst by centrifugation, washing and drying of sample, during each cycle of reusability. No significant changes in neither the dye degradation efficiency loss nor photocatalyst structure occur.

\section{Materials and Methods}

\subsection{Materials}

All the reagents in this study were commercial products purchased from Sigma-Aldrich (Darmstadt, Germany) and Merck (St. Louis, USA and were used without further purification. Nanopure water was obtained from a water purification system.

\subsection{Experimental-Synthesis Nanocomposites}

\subsubsection{Synthesis of $\mathrm{ZnO}($ Stearic Acid)- $\mathrm{ZnO}(\mathrm{SA})$}

$\mathrm{ZnO}$-stearic acid nanocomposite was synthesized as described in a previous paper [36]. In a typical procedure, $\mathrm{ZnSO}_{4}\left(1 \mathrm{~mol} \mathrm{~L}^{-1}\right)$ was mixed with $\mathrm{Na}_{2} \mathrm{CO}_{3}\left(1 \mathrm{~mol} \mathrm{~L}^{-1}\right) / \mathrm{NaOH}\left(1 \mathrm{~mol} \mathrm{~L}^{-1}\right)(1: 1)$ to bear a $\mathrm{ZnO}$ hydrogel; then stearic acid (SA) $4.0 \times 10^{-1} \mathrm{~mol} \mathrm{~L}^{-1}$ aqueous solution was added to the $\mathrm{ZnO}$ hydrogel solution under stirring at room temperature; the suspension was stirred at $60^{\circ} \mathrm{C}$ followed by an aging period of $24 \mathrm{~h}$ at room temperature. The sample was washed and dried at $80^{\circ} \mathrm{C}$ for $72 \mathrm{~h}$. Analysis: \% found (calculated) for $\mathrm{ZnO}\left(\mathrm{C}_{18} \mathrm{H}_{36} \mathrm{O}_{2}\right)_{0.38} \cdot 0.5 \mathrm{H}_{2} \mathrm{O}, \mathrm{C}: 41.94(41.65), \mathrm{H}: 7.20(7.22)$.

\subsubsection{Synthesis of Compounds Vanadium Pentoxide}

$\mathrm{V}_{2} \mathrm{O}_{5}$ xerogel, a mixture of t-butyl alcohol and orthorhombic $\mathrm{V}_{2} \mathrm{O}_{5}$ was refluxed for $6 \mathrm{~h}$ to form the xerogel. Water was added to the resulting dark yellow solid and the remaining t-butyl alcohol was removed with excess water under vacuum. Water was added to yield a suspension. The material was aged at room temperature yielding a red-brown colloidal $\mathrm{V}_{2} \mathrm{O}_{5}$ [37].

$\mathrm{V}_{2} \mathrm{O}_{5}$ (hexadecylamine) $\mathrm{V}_{2} \mathrm{O}_{5}$ (HDA). A solution of $10^{-3} \mathrm{~mol}$ of hexadecylamine (HDA) in pure ethanol, previously degassed was mixed with $2 \times 10^{-3}$ mol of vanadium triisopropoxide (VOTPP) [37]. The yellow solution, obtained after vigorous stirring in an argon atmosphere for $1 \mathrm{~h}$, was then hydrolyzed by adding $15 \mathrm{~mL}$ of water. The orange suspension obtained after stirring for $24 \mathrm{~h}$. and subjected to a hydrothermal treatment in a Teflon lined autoclave at $180{ }^{\circ} \mathrm{C}$ for 6 days. From the results, an orange solid was separated, washed with pure ethanol and water, the sample was washed and dried at $80{ }^{\circ} \mathrm{C}$ for $72 \mathrm{~h}$ Analysis: \% found (calculated) for $\mathrm{V}_{2} \mathrm{O}_{5}(\mathrm{HDA})_{0.83} \cdot \times 1.8 \mathrm{H}_{2} \mathrm{O}$. Anal. C: $38.32(39.06)$; $\mathrm{H}: 7.89(8.05)$; N: 2.79(2.56)

$\mathrm{V}_{2} \mathrm{O}_{5}$ orthorhombic, Sigma-Aldrich (Darmstadt, Germany)

The samples were mixed mechanically in an agate mortar (relation $w / w$ ). These samples were denoted as $\mathrm{ZnO}(\mathrm{SA}) / \mathrm{V}_{2} \mathrm{O}_{5} ; \mathrm{ZnO}(\mathrm{SA}) / \mathrm{V}_{2} \mathrm{O}_{5}$-xerogel and $\mathrm{ZnO}(\mathrm{SA}) / \mathrm{V}_{2} \mathrm{O}_{5}(\mathrm{HDA})$. 


\subsection{Photocatalytic Experiments}

The photocatalytic activity of nanocomposites was studied for the degradation in visible light irradiation of methylene blue as a pollutant model. For this study, the characteristic absorption peak of $\mathrm{MB}$ at $664 \mathrm{~nm}$ was monitored using a UV-vis spectrophotometer at regular intervals of time and the corresponding absorption spectra. The photocatalytic activity of the products was evaluated by measuring the degradation of methylene blue (MB) in water. The nanocomposite $\mathrm{ZnO}(\mathrm{SA})(10 \mathrm{mg})$ and compounds of $\mathrm{V}_{2} \mathrm{O}_{5}$ in different proportions in $25 \mathrm{~mL}$ of a $1 \times 10^{-5} \mathrm{~mol} \mathrm{~L}^{-1}$ which solution phosphate buffer prepared mixing solutions of $\mathrm{Na}_{2} \mathrm{HPO}_{4}$ and $\mathrm{NaH}_{2} \mathrm{PO}_{4}$. Prior to irradiation, the suspension was magnetically stirred for $30 \mathrm{~min}$, to establish an adsorption/desorption equilibrium.

The suspensions were irradiated by a $300 \mathrm{~W}$ Xe arc lamp (Newport) with a UVIR-CUT filter at $\lambda \geq 400 \mathrm{~nm}$, the luminance of the light source over the reactant solution was $0.5 \mathrm{Sun}$. All samples were constant magnetic stirring to ensure a higher level of homogeneity of the photocatalyst in the suspension. The $\mathrm{MB}$ concentration after equilibration was regarded as the initial concentration $\left(\mathrm{C}_{0}\right)$ and was monitored in the UV-vis spectra of the solution (Perkin Elmer Lambda 35, Shelton, USA), using nanopure water as a reference.

\subsection{Characterization}

X-ray diffraction (XRD) analyses of the products were performed using a Bruker D8 Advance (Cu K $\alpha \lambda=1.5418 \AA$ ). The Scanning Electron Microscopy (SEM) and images were obtained by using an EVO MA 10 ZEISS microscope. X-ray photoelectron spectra (XPS) were obtained in a STAIB system with a RQ-300 X-ray source, using monochromated Al K $\alpha$ X-rays $(1486.6 \mathrm{eV}, 75 \mathrm{~W})$. The charge referencing was done against adventitious carbon ( $\mathrm{C} 1 \mathrm{~s} 285 \mathrm{eV})$. Zn 2p, V 2p, O 1s and C1s energy regions were scanned with several sweeps until a good signal-to-noise ratio was observed. Chemical analysis was obtained by using (SISONS ES-1108). The diffuse reflectance UV-vis spectra were recorded in the range of $200-800 \mathrm{~nm}$ using a Perkin Elmer Lambda 35 spectrometer. Reflectance measurements were converted to absorption spectra using the Kubelka-Munk function. Fourier transform infrared (FTIR) spectra were recorded an FT/IR-4600 Jasco spectrometer (Tokyo, Japan).

\section{Conclusions}

In summary, we have reported the successfull fabrication of the new heterojunction of two 2D hybrid semiconductors, $\mathrm{ZnO}(\mathrm{SA}) / \mathrm{V}_{2} \mathrm{O}_{5}(\mathrm{HDA})$ exhibiting improved photocatalytic activity than the pristine zinc oxide in the degradation of methylene blue under visible light. The efficacy of the products described as catalysts for the photooxidation of organic pollutants is associated with the surface properties of 2D hybrid nanocomposites, collection efficiency for visible light as well as the presence of organic surfactant in the interlaminar spaces of $\mathrm{ZnO}$ and $\mathrm{V}_{2} \mathrm{O}_{5}$ that favors the adsorption of the dye on the surface of semiconductors. The nanocomposites of $\mathrm{V}_{2} \mathrm{O}_{5}$ effectively inhibit the recombination of photogenerated electron/hole pairs. The products are recyclables and seen as potentially useful for environmental issues remediation.

Supplementary Materials: The following are available online at http:/ /www.mdpi.com/2073-4344/8/9/374/s1, Figure S1. XPS survey spectra; Figure S2. (a) Images SEM of $\mathrm{ZnO}(\mathrm{SA}) / \mathrm{V}_{2} \mathrm{O}_{5}(\mathrm{HDA})$ (b) Element mappings $\mathrm{Zn}$ and $\mathrm{V}$, (c) and (d) Element mappings Zn and V (x5); Figure S3. The UV-visible diffuse reflectance was measured for $\mathrm{ZnO}(\mathrm{SA}), \mathrm{V}_{2} \mathrm{O}_{5}(\mathrm{HDA})$ and $\mathrm{ZnO}(\mathrm{SA}) / \mathrm{V}_{2} \mathrm{O}_{5}(\mathrm{HDA})$; Figure S4. Band gap of samples for $\mathrm{ZnO}(\mathrm{SA})$ and $\mathrm{V}_{2} \mathrm{O}_{5}(\mathrm{HDA})$; Figure S5. Photocatalytic performance of the samples for the degradation of MB solution; Figure S6. Absorption spectra with time of visible light exposure sample $\mathrm{ZnO}(\mathrm{SA}) / \mathrm{V}_{2} \mathrm{O}_{5}(\mathrm{HDA})$ (1:0.1); Figure S7. Recycling test of $\mathrm{MB}$ photodegradation under visible light of $\mathrm{ZnO}(\mathrm{SA}) / \mathrm{V}_{2} \mathrm{O}_{5}(\mathrm{HDA})(1: 0.25)$ and Table S1. Molar composition of samples prepared and degradation of $\mathrm{MB}$.

Author Contributions: J.A. and N.C. conceived and designed the experiments. N.C. performed the experiments. E.B., C.S.-T. and G.G. analyzed the data and discussed results. J.A. contributed reagents/materials/analysis tools. E.B. and G.G. wrote the paper.

Funding: This research received no external funding. 
Acknowledgments: Work supported by UTEM, UCh, FONDECYT 1151189, 1171803, Basal Financing Program CONICYT, FB0807 (CEDENNA). CMST acknowledges the support from the Spanish MINECO projects PHENTOM (FIS2015-70862-P), Severo Ochoa (SEV-2013-0295) and from the CERCA Programme/Generalitat de Catalunya. Conicyt-Programa Fondequip XPS EQM 140044.

Conflicts of Interest: The authors declare no conflict of interest.

\section{References}

1. Chan, S.H.; Wu, T.Y.; Juan, J.C.; The, C.Y. Recent developments of metal oxide semiconductors as photocatalysts in advanced oxidation processes (AOPs) for treatment of dye waste-water. Chem. Technol. Biotechnol. 2011, 86, 1130-1158. [CrossRef]

2. Ray, C.; Pal, T. Recent advances of metal-metal oxide nanocomposites and their tailored nanostructures in numerous catalytic applications. J. Mater. Chem. A 2017, 5, 9465-9487. [CrossRef]

3. Lang, X.; Chen, X.; Zhao, J. Heterogeneous visible light photocatalysis for selective organic transformations. Chem. Soc. Rev. 2014, 43, 473-486. [CrossRef] [PubMed]

4. Ibhadon, A.O.; Fitzpatrick, P. Heterogeneous Photocatalysis: Recent Advances and Applications. Catalysts 2013, 3, 189-219. [CrossRef]

5. Hernandez, S.; Hidalgo, D.; Sacco, A.; Chiodoni, A.; Lamberti, A.; Cauda, V.; Tresso, E.; Saracco, G. Comparison of photocatalytic and transport properties of $\mathrm{TiO}_{2}$ and $\mathrm{ZnO}$ nanostructures for solar-driven water splitting. Phys. Chem. Chem. Phys. 2015, 17, 7775-7786. [CrossRef] [PubMed]

6. Xia, Y.; Wang, J.; Chen, R.; Zhou, D.; Xiang, L. A Review on the Fabrication of Hierarchical ZnO Nanostructures for Photocatalysis Application. Crystals 2016, 6, 148. [CrossRef]

7. Banerjee, S.; Dionysiou, D.D.; Pillai, S.C. Self-Cleaning applications of $\mathrm{TiO}_{2}$ by photo-induced hydrophilicity and photocatalysis. App. Catal. B Environ. 2015, 176-177, 396-428. [CrossRef]

8. Chen, X.; Wu, Z.; Liu, D.; Gao, Z. Preparation of ZnO photocatalyst for the efficient and rapid photocatalytic degradation of Azo dyes. Nanoscale Res. Lett. 2017, 12, 143. [CrossRef] [PubMed]

9. Lee, K.M.; Lai, C.W.; Ngai, K.S.; Juan, J.C. Recent developments of zinc oxide based photocatalyst in water treatment technology: A review. Water Res. 2016, 88, 428-448. [CrossRef] [PubMed]

10. Wang, J.; Xia, Y.; Dong, Y.; Chen, R.; Xiang, L.; Komarneni, S. Defect-rich ZnO nanosheets of high surface area as an efficient visible-light photocatalyst. App. Catal. B Environ. 2016, 192, 8-16. [CrossRef]

11. Song, X.; Dong, D.; Yang, P. Formation of nanoplate-based clew-like ZnO mesocrystals and their photocatalysis application. RSC Adv. 2016, 6, 51544-51551. [CrossRef]

12. Fageria, P.; Gangopadhyay, S.; Pande, S. Synthesis of $\mathrm{ZnO} / \mathrm{Au}$ and $\mathrm{ZnO} / \mathrm{Ag}$ nanoparticles and their photocatalytic application using UV and visible light. RSC Adv. 2014, 4, 24962-24972. [CrossRef]

13. Zhang, Y.; Xu, J.; Xu, P.; Zhu, Y.; Chen, X.; Yu, W. Decoration of ZnO nanowires with Pt nanoparticles and their improved gas sensing and photocatalytic performance. Nanotechnology 2010, 21, 285501-285508. [CrossRef] [PubMed]

14. Mendoza-Mendoza, E.; Nuñez-Briones, A.G.; García-Cerda, L.A.; Peralta-Rodríguez, R.D.; Montes-Luna, A.J. One-step synthesis of $\mathrm{ZnO}$ and $\mathrm{Ag} / \mathrm{ZnO}$ heterostructures and their photocatalytic activity. Ceram. Int. 2018, 44, 6176-6180. [CrossRef]

15. Mani, J.; Sakeek, H.; Habouti, S.; Dietze, M.; Es-Souni, M. Macro-meso-porous $\mathrm{TiO}_{2}, \mathrm{ZnO}_{\text {and } \mathrm{ZnO}-\mathrm{TiO}}$ composite thick films. Properties and application to photocatalysis. Catal. Sci. Technol. 2012, 2, 379-385. [CrossRef]

16. Balachandran, S.; Prakash, N.; Thirumalai, K.; Muruganandham, M.; Sillanpää, M.; Swaminathan, M. Facile construction of heterostructured $\mathrm{BiVO}_{4}-\mathrm{ZnO}$ and its dual application of greater solar photocatalytic activity and self-cleaning property. Ind. Eng. Chem. Res. 2014, 53, 8346-8356. [CrossRef]

17. Sun, C.; Fu, Y.; Wang, Q.; Xing, L.; Liu, B.; Xue, X. Ultrafast piezo-photocatalytic degradation of organic pollutions by $\mathrm{Ag}_{2} \mathrm{O} /$ tetrapod-ZnO nanostructures under ultrasonic/UV exposure. RSC Adv. 2016, 6, 87446-87453. [CrossRef]

18. Kandjani, K.; Sabri, Y.; Periasamy, S.; Zohora, N.; Amin, M.; Nafady, A.; Bhargava, S. Controlling core/shell formation of nanocubic $\mathrm{p}-\mathrm{Cu}_{2} \mathrm{O} / \mathrm{n}-\mathrm{ZnO}$ toward enhanced photocatalytic performance. Langmuir 2015, 39, 10922-10930. [CrossRef] [PubMed] 
19. Vikas, L.S.; Vanaja, K.A.; Subha, P.P.; Jayaraj, M.K. Fast UV sensing properties of n-ZnO nanorods/p-GaN heterojunction. Sens. Actuators A 2016, 242, 116-122. [CrossRef]

20. Adhikari, S.; Sarkar, D.; Madras, G. Highly efficient $\mathrm{WO}_{3}-\mathrm{ZnO}$ mixed oxides for photocatalysis. RSC Adv. 2015, 5, 11895-11904. [CrossRef]

21. Ahmeda, L.T.; Ma, M.; Edvinsson, T.; Zhua, J. A facile approach to ZnO/CdS nanoarrays and their photocatalytic and photoelectrochemical properties. App. Catal. B Environ. 2013, 138-139, 175-183.

22. Zaera, F. New challenges in heterogeneous catalysis for the 21st century. Catal. Lett. 2012, 142, 501-516. [CrossRef]

23. Ebrahimi, M.; Samadi, M.; Yousefzadeh, S.; Soltani, M.; Rahimi, A.; Chou, T.; Chen, L.; Chen, K.; Moshfegh, A. Improved solar-driven photocatalytic activity of hybrid graphene quantum dots/ZnO nanowires: A direct Z-scheme mechanism. ACS Sustain. Chem. Eng. 2017, 5, 367-375. [CrossRef]

24. Colombo, E.; Li, W.; Bhangu, S.; Ashokkumar, M. Chitosan microspheres as a template for $\mathrm{TiO}_{2}$ and $\mathrm{ZnO}$ microparticles: Studies on mechanism, functionalization and applications in photocatalysis and $\mathrm{H}_{2} \mathrm{~S}$ removal. RSC Adv. 2017, 7, 19373-19383. [CrossRef]

25. Anastasio, P.; Del Giacco, T.; Germani, R.; Spretic, N.; Tiecco, M. Structure effects of amphiphilic and non-amphiphilic quaternary ammonium salts on photodegradation of Alizarin Red-S catalysed by titanium dioxide. RSC Adv. 2017, 7, 361-368. [CrossRef]

26. Low, J.; Cao, S.; Yu, J.; Wageh, S. Two-dimensional layered composite photocatalysts. Chem. Commun. 2014, 50, 10768-10777. [CrossRef] [PubMed]

27. Li, Y.; Li, Y.L.; Sa, B.; Ahujad, R. Review of two-dimensional materials for photocatalytic water splitting from a theoretical perspective. Catal. Sci. Technol. 2017, 7, 545-559. [CrossRef]

28. Zhang, Z.; Huang, J.; Zhang, M.; Yuan, Q.; Dong, B. Ultrathin hexagonal SnS2 nanosheets coupled with g- $\mathrm{C}_{3} \mathrm{~N}_{4}$ nanosheets as $2 \mathrm{D} / 2 \mathrm{D}$ heterojunction photocatalysts toward high photocatalytic activity. Appl. Catal. B 2015, 163, 298-305. [CrossRef]

29. Yuan, C.; Hung, C.; Yuan, C.; Wen, H. Preparation and application of immobilized surfactant-modified $\mathrm{PANi}-\mathrm{CNT} / \mathrm{TiO}_{2}$ under visible-light irradiation. Materials 2017, 10, 877. [CrossRef] [PubMed]

30. Zhu, X.; Yuan, C.; Chen, C. Photocatalytic degradation of pesticide pyridaben. 3. In surfactant $/ \mathrm{TiO}_{2}$ aqueous dispersions. Environ. Sci. Technol. 2007, 41, 263-269. [CrossRef] [PubMed]

31. Duta, M.; Perniu, D.; Duta, A. Photocatalytic zinc oxide thin films obtained by surfactant assisted spray pyrolysis deposition. App. Surf. Sci. 2014, 306, 80-88. [CrossRef]

32. Hao, C.; Wang, J.; Cheng, Q.; Bai, Y.; Wang, X.; Yang, Y. Anionic surfactants-assisted solution-phase synthesis of $\mathrm{ZnO}$ with improved photocatalytic performance. J. Photochem. Photobiol. A Chem. 2017, 332, 384-390. [CrossRef]

33. Benavente, E.; Navas, D.; Devis, S.; Segovia, M.; Sotomayor-Torres, C.; González, G. Composites of laminar nanostructured ZnO and VOx-Nanotubes hybrid as visible light active photocatalysts. Catalysts 2018, 8, 93. [CrossRef]

34. Yin, H.; Yu, K.; Hu, J.; Song, C.; Guo, B.; Wang, Z.; Zhu, Z. Novel photoluminescence properties and enhanced photocatalytic activities for $\mathrm{V}_{2} \mathrm{O}_{5}$-loaded $\mathrm{ZnO}$ nanorods. Dalton Trans. 2015, 10, 4671-4678. [CrossRef] [PubMed]

35. Zou, C.W.; Rao, Y.F.; Alyamani, A.; Chu, W.; Chen, M.J.; Patterson, D.A.; Emanuelsson, E.A.; Gao, W. Heterogeneous lollipop-like $\mathrm{V}_{2} \mathrm{O}_{5} / \mathrm{ZnO}$ Array: A promising composite nanostructure for visible light photocatalysis. Langmuir 2010, 14, 11615-11620. [CrossRef] [PubMed]

36. Aslam, M.; Ismail, I.; Almeelbi, T.; Salah, N.; Chandrasekaran, S.; Hameed, A. Enhanced photocatalytic activity of $\mathrm{V}_{2} \mathrm{O}_{5}-\mathrm{ZnO}$ composites for the mineralization of nitrophenols. Chemosphere 2014, 117, 115-123. [CrossRef] [PubMed]

37. Segovia, M.; Lemus, K.; Moreno, M.; Santa Ana, M.A.; González, G.; Ballesteros, B.; Sotomayor, C.; Benavente, E. Zinc oxide/carboxylic acid lamellar structures. Mater. Res. Bull. 2011, 46, 2191-2195. [CrossRef]

38. O’Dwyer, C.; Navas, D.; Lavayen, V.; Benavente, E.; Santa Ana, M.A.; González, G.; Newcomb, S.B.; Sotomayor Torres, C.M. Nano-Urchin: The formation and structure of high-density spherical clusters of vanadium oxide nanotubes. Chem. Mater. 2006, 13, 3016-3022. [CrossRef]

39. Asim, N.; Radiman, S.; Yarmo, M.A. Preparation and characterization of core-shell polyaniline $/ \mathrm{V}_{2} \mathrm{O}_{5}$ nanocomposite via microemulsion method. Mater. Lett. 2008, 62, 1044-1047. [CrossRef] 
40. Martha, S.; Das, D.P.; Biswal, N.; Parida, K.M. Facile synthesis of visible light responsive $\mathrm{V}_{2} \mathrm{O}_{5} / \mathrm{N}_{1} \mathrm{~S}-\mathrm{TiO}_{2}$ composite photocatalyst: Enhanced hydrogen production and phenol degradation. J. Mater. Chem. 2012, 22, 10695-10703. [CrossRef]

41. Xu, Y.; Schoonen, M. The absolute energy positions of conduction and valence bands of selected semiconducting minerals. Am. Mineral. 2000, 85, 543-556. [CrossRef]

42. Mendive, C.B.; Bahnemann, D.W.; Blesa, M.A. Microscopic characterization of the photocatalytic oxidation of oxalic acid adsorbed onto $\mathrm{TiO}_{2}$ by FTIR-ATR. Catal. Today 2005, 101, 237-244. [CrossRef]

43. O’Dwyer, C.; Lavayen, V.; Newcomb, S.B.; Santa Ana, M.A.; Benavente, E.; González, G.; Sotomayor-Torres, C.M. Vanadate conformation variations in vanadium pentoxide nanostructures. J. Electrochem. Soc. 2007, 154, K29-K35. [CrossRef]

44. Liu, H.R.; Shao, G.X.; Zhao, J.F.; Zhang, Z.X.; Zhang, Y.; Liang, J.; Liu, X.G.; Jia, H.S.; Xu, B.S. Worm-like $\mathrm{Ag} / \mathrm{ZnO}$ core-shell heterostructural composites: Fabrication, characterization, and photocatalysis. J. Phys. Chem. C 2012, 116, 16182-16190. [CrossRef]

45. Kumar, S.; Sharma, V.; Bhattacharyya, K.; Krishnana, V. N-doped ZnO-MoS 2 binary heterojunctions: Dual role of 2D MoS2 in the enhancement of photostability and photocatalytic activity under visible light irradiation for tetracycline degradation. Mater. Chem. Front. 2017, 1, 1093-1106. [CrossRef]

46. Hong, Y.; Jiang, Y.; Li, C.; Fan, W.; Yan, X.; Yan, M.; Shi, W. In-situ synthesis of direct solid-state Z-scheme $\mathrm{V}_{2} \mathrm{O}_{5} / g-\mathrm{C}_{3} \mathrm{~N}_{4}$ heterojunctions with enhanced visible light efficiency in photocatalytic degradation of pollutants. Appl. Catal. B. 2016, 180, 663-673. [CrossRef]

47. Yan, M.; Wu, Y.; Zhu, F.; Hua, Y.; Shi, W. The fabrication of a novel $\mathrm{Ag}_{3} \mathrm{VO}_{4} / \mathrm{WO}_{3}$ heterojunction with enhanced visible light efficiency in the photocatalytic degradation of TC. Phys. Chem. Chem. Phys. 2016, 18, 3308-3315. [CrossRef] [PubMed]

48. Tong, Z.H.; Yang, D.; Sun, Y.Y.; Tian, Y.; Jiang, Z.Y. In situ fabrication of $\mathrm{Ag}_{3} \mathrm{PO}_{4} / \mathrm{TiO}_{2}$ nanotube heterojunctions with enhanced visible-light photocatalytic activity. Phys. Chem. Chem. Phys. 2015, 17, 12199-12206. [CrossRef] [PubMed]

49. Dong, F.; Sun, Y.; Fu, M. Enhanced visible light photocatalytic activity of $\mathrm{V}_{2} \mathrm{O}_{5}$ cluster modified N-Doped $\mathrm{TiO}_{2}$ for degradation of toluene in air. Int. J. Photoenergy 2012, 10, 569716.

(C) 2018 by the authors. Licensee MDPI, Basel, Switzerland. This article is an open access article distributed under the terms and conditions of the Creative Commons Attribution (CC BY) license (http://creativecommons.org/licenses/by/4.0/). 